\title{
Teaching Reform for an 8051 Microcontroller Course Based on E-learning
}

\author{
Wuxiong $\mathrm{Xu}$ \\ School of Electronic and Information Engineering, Hubei University of Science and Technology, \\ Xianning 437100, China \\ xwxiong@qq.com
}

Keywords: Teaching reform; microcontroller course; E-learning; assisted learning.

\begin{abstract}
An 8051 microcontroller course is a core professional course in engineering major in many universities. The traditional teaching (face to face teaching) method cannot achieve satisfactory teaching effect. So other teaching method should be applied to improve teaching effect. E-learning is a relatively good online teaching and learning method at home and abroad. In this paper the teaching reform for an 8051 microcontroller course is researched and the idea of the reform is that the E-learning teaching method is combined with the traditional teaching one. Firstly the problems from the traditional teaching method are analyzed; secondly a structure of an E-learning teaching system for an 8051 microcontroller is present. Finally an implementation plan of the E-learning teaching is also proposed. This E-learning teaching method can eliminate some problems from the traditional teaching method to improve teaching effect and quality.
\end{abstract}

\section{Introduction}

A microcontroller is more and more widely used in industry, agriculture, national defense and the daily life [1, 2]. Many colleges and universities have offered the "microcontroller" course, especially in electronics and electrical engineering and other engineering specialty [3]. The course is very importance as a compulsory course.

In most of colleges and universities in china, students' learning scores are not very ideal [4]. The result is caused by the following reasons: (1) Many schools has still used the traditional teaching way that is as known the "cramming teaching method" in the classroom. Students' learning is passive and so they not interested in learning in the way. (2) The teaching means is single. The general teaching means is to use Power Point (PPT) software. However PPT plays too fast so that students are difficult to keep up with the pace. (3) The contents of this course are too much, but the class hours are less and so students are not easy to understand the knowledge points. (4) The experiment teaching still exists some problems. For example, the experiment equipment is obsolete and shortage; the students have little chance to do experiments.

From the above analysis, there are still some problems for the microcontroller course using traditional teaching methods in classroom. It is an urgent need for other approaches to assist teaching to make up for the deficiency of the traditional teaching methods.

In this paper, the teaching reform for an 8051 microcontroller course is researched and the idea of the reform is that the E-learning teaching method is combined with the traditional teaching one. This paper is organized as follows. Section 2 outlines E-learning. Section 3 presents the structure of E-learning teaching system for an 8051 microcontroller course. Section 4 puts forward an implementation plan of the E-learning teaching. Section 5 draws a conclusion.

\section{E-learning Overview}

E-learning is an open interactive learning mode based on network technology [5]. E-learning teaching platform assembles the large amounts of data, multimedia material, programs, teaching software, interest discussion groups, with a new communication mechanism and abundant learning environment, and provides the online learning anytime, anywhere, not subject to the restrictions of 
time and space [5]. E-Learning does not just mean distance education, and online teaching can also play an important role in the traditional campus teaching. E-learning entering the campus is not to completely replace the traditional teaching, but to continue colliding with the traditional teaching. In collisions the tradition teaching is fused with E-learning and this gradually forms a new effective teaching method system based on information technology [6].

\subsection{Features of E-learning}

Features of E-learning are as follows.

1). Networking of knowledge: Knowledge is no longer a book or several reference books but a database involving much professional knowledge. Under the support of the database, the knowledge system will be redivided, learning content will be reassembled, and learning and research methods will be a new change [7].

2). Immediate nature of learning: Learning can be endless throughout the full year, whether it is in school, home or on the road. Time has become a key factor in learning. Students can follow their own arrangements for the time to learn, not limited to the school custom class.

3). Timely and continuous updates of Learning contents: All kinds of learning resources keep updates which are fused with much other information relating to students including new achievements in scientific research, social employment demand and so on so that the resources for students is more practical.

\subsection{Development of E-learning}

In the United States, E-learning education is almost everywhere. In 2005 there are about 500000 primary and secondary school students to participate in online education. In other developed countries, such as Sweden, France, Germany, and Australia and so on, the construction of e-learning system is more perfect, its technology is more mature, and there are many successful application cases in education and training [8].

At present, major E-learning customers are large firm and enterprises in China. E-learning is applied to the enterprise, colleges and universities, higher vocational colleges, technical schools, etc. This application is basically in the form of network teaching platform.

In a word, the developed countries have very mature E-learning technology and its application has promoted the improvement of the quality of national education and obtained the huge social benefit and economic benefit. However the development of E-learning in China is not ideal which is still in its infancy. Therefore in higher education, the introduction of E-learning teaching is very necessary.

\section{An structure of an E-learning teaching system for an 8051 microcontroller}

According to a system structure and characteristics of an 8051 microcontroller course, the structure of an E-learning system for an 8051 Microcontroller course is designed as shown in Fig. 1.

Students can learn online the 8051 microcontroller course and teachers can also carry on the online teaching activity by the system. The structure of the system consists of a system management system, a teaching support system and a teaching resource management system [9]. Its function is described as follows.

1). System management system

The functions of the system management system mainly include user management and system maintenance. The functions of the user management are the management of the identity and rights of legitimate users. Its specific functions are to assign usernames and passwords to new users and to assign different permissions to students and teachers. The functions of the system maintenance are to maintain the performance and security of the E-learning platform, to timely repair the fault, and to ensure stable operation.

2). Teaching support system

The teaching support system can provide support to students' learning and teachers' teaching activities online. The system consists of a question answering subsystem, a homework management subsystem, a simulation experiment subsystem, a self test subsystem, an online test subsystem, a test 
library management subsystem, an online interaction subsystem, a course evaluation subsystem, a teaching management system, a learning subsystem, a teaching subsystem and a teaching resources editing subsystem and so on.

Teaching support system

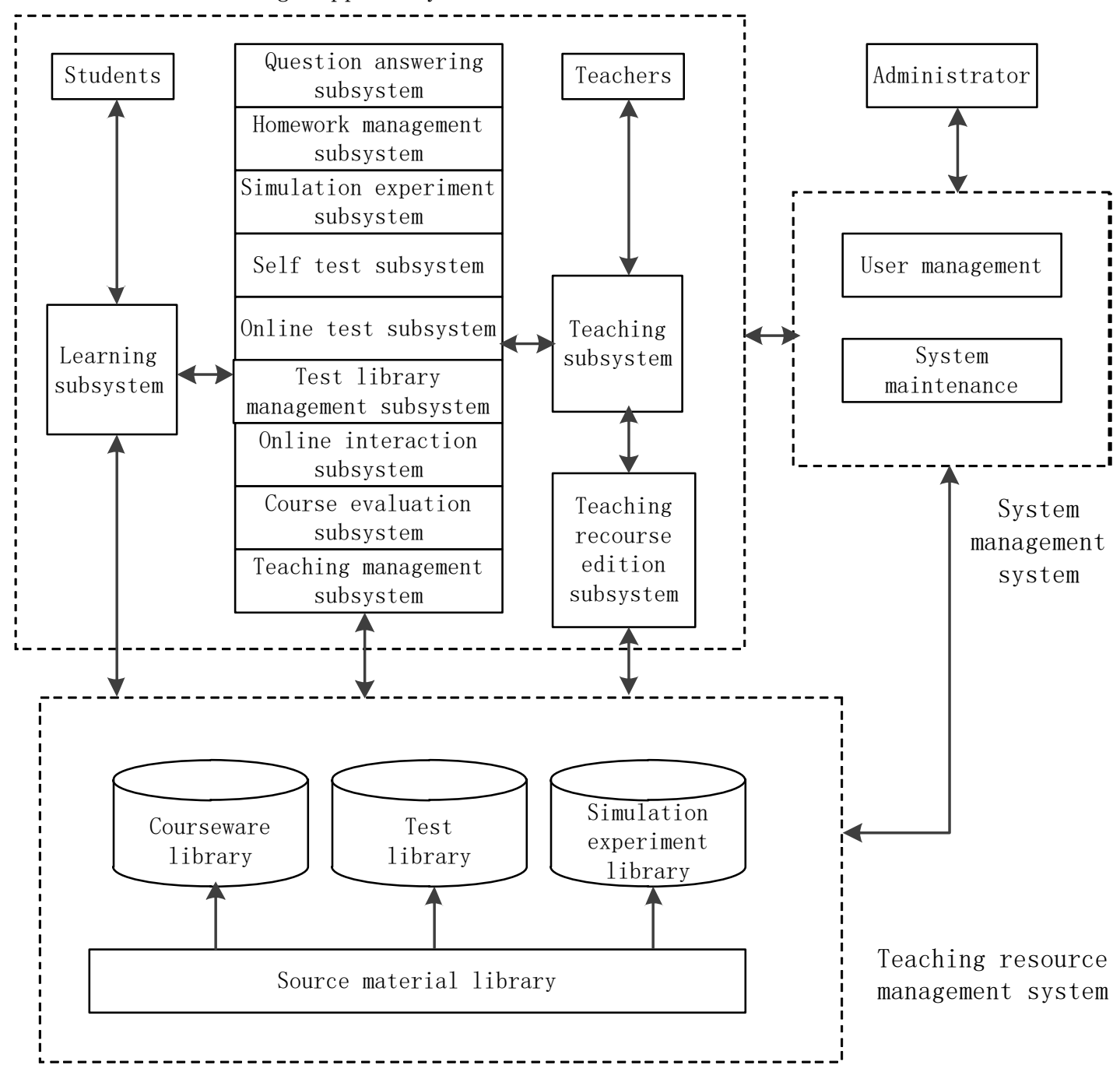

Fig. 1 The structure of E-learning system for an 8051 Microcontroller course

The functions of the question answering subsystem: students can give their question online and teacher can answer the question in real time or later.

The functions of the homework management subsystem: teacher can give a homework assignment through the subsystem; students must submit the assignment in time; teacher must correct students' assignment; the subsystem can store students' scores of assignment and students can also query their scores.

The functions of simulation experiment subsystem: students can access a simulation laboratory for an 8051 microcontroller based on Proteus simulation software to finish simulation experiment; after the experiment, the students must submit the experiment reports online; the teachers can correct the experiment reports through the system; the system can record the student's experiment scores and students can also query them.

The functions of the self-test subsystem: students can carry out unit test through the system, and the test system gives the test results so that students check the situation of their knowledge points.

The function of the online test subsystem: teachers can give a middle or final test to the students; papers can be generated through a test library, teachers can mark the papers online, the system can record scores and student can query their scores.

The functions of the Test library management subsystem: teachers can add, delete and edit contents of the library and can maintain the library. 
The functions of the online interaction subsystem: teachers can make interactive communication with students for interest issues through the subsystem.

The functions of the course evaluation subsystem: students can evaluate the teaching quality of teachers through the system.

The functions of the teaching management: teachers can manage the students' roster, curriculum, teaching schedule etc.

The functions of the learning subsystem: students can learn an 8051microcontroller course and attend other online teaching activities as mentioned above.

The functions of the teaching subsystem: teachers can prepare teaching materials and carry out the teaching activities as mentioned above through the system.

The functions of the teaching resources edition subsystem: teachers can process the teaching material to produce courseware, examination questions and experiments and other teaching materials through the system.

3). Teaching resource management system

The teaching resource management system includes the source material library, the courseware library, the test library and the simulation experiment library, whose functions is to manage the teaching resources.

The source material library contains the text, pictures, animation, audio and video and other raw materials to provide material for the courseware library, the test library and the simulation experiment laboratory.

The courseware library contains the courseware of the microcontroller course. There are different Types of the courseware in the library such as PPT, teachers' teaching videos, etc. Students can choose the courseware according to their own needs.

The test library contains examination questions of each chapter in the microcontroller course to provide test sources for students' self-test or a middle or final test.

The functions of the simulation experiment library: the library consists of a simulation experiment platform and experiment materials; the simulation platform is based on Proteus software whose merit is to almost real simulation an 8051microcontroller; in the E-learning system, the construction of a simulation laboratory is a beneficial supplement to the construction of the real laboratory.

\section{Implementation plan of the E-learning course for an 8051 microcontroller}

This E-learning teaching is a kind of supplementary teaching means to the traditional teaching means which can deepen students' understanding of the knowledge and cultivate students' autonomous learning ability. The implementation plan is as follows.

Step 1: The teachers log into the teaching subsystem in E-learning system, then enter the teaching resource management system and update the source material library.

Step 2: Before the classroom teaching, students should be asked to log into the learning subsystem to prepare lessons.

Step 3: After the classroom teaching, students should be asked to log into the learning subsystem to review the finished course. If students have any questions, they can enter the question answering subsystem to leave their questions. Teachers regularly answer these questions. Students can also access the online interaction subsystem to communicate real time the questions with teachers at the prescribed time.

Step 4: Students are asked to log into the homework management subsystem to finish the homework and submit it online. Teachers should mark the submitted homework.

Step 5: After finishing each unit of learning, students need to log into the self-test subsystem for self-testing to discover the apprehended knowledge points.

Step 6: Before an experiment, students are asked to prepare experiment online. Students must access the simulation experiment subsystem to carry out the simulation experiment. After finishing the simulation experiment, students can go to a laboratory doing real experiment. 
Step 7: Students are asked to attend a middle or final test per semester online. Hence they need to log on the subsystem test to complete the corresponding test.

Step 8: At the end of the semester, students can evaluate the teacher's teaching level through the evaluation subsystem Course.

Step 9: At the end of the semester, the teacher can manage and evaluate students' performance through the teaching management subsystem.

\section{Conclusion}

E-learning is an online learning style through the network. This learning may not be subject to the limit of time and space. It is used as a supplement to the traditional face-to-face education. This e-learning teaching is very helpful to an 8051 microcontroller teaching. The above E-learning assisted teaching and its implementation plan can meet the needs of students' autonomous learning and teachers' online teaching. It provides a kind of new method for in-depth learning an 8051 microcontroller course.

\section{Acknowledgment}

This paper is financial supported by Research Project of Science and Technology of the Hubei Provincial Department of Education (No. B2015079).

\section{References}

[1]. I. A. Odigwe, O. O. Ologun, and O. Olatokun, "A microcontroller-based active solar water heating system for domestic applications,” International Journal of Renewable Energy Research, vol.3, pp. 837-845, April, 2013.

[2]. S. Shrivastava, J. Rawat, and A. Agrawal, "Controlling DC motor using microcontroller (PIC16F72) with PWM,” International Journal of Engineering Research, vol. 1, pp. 45-47, December 2012.

[3]. A. Lozano-Nieto, "Microcontroller-based experiments for a control systems course in electrical engineering technology,” International Journal of Electrical Engineering Education, vol. 51, pp. 43-53, January 2014.

[4]. C. Yanhui, "Exploration on Teaching Reform Mode of Microcontroller," The Guide of Science \& Education, vol. 7, pp. 52-55, June, 2013.

[5]. F. Rennie, and T. Morrison, E-learning and social networking handbook: Resources for higher education, 2nd ed., New York: Routledge, 2013, pp. 12-20.

[6]. B. S. Bell, and J. E. Federman, “E-learning in postsecondary education,” The Future of Children, vol. 23, pp. 165-185, January, 2013.

[7]. E. Y. Huang, S. W. Lin, and T. K. Huang, "What type of learning style leads to online participation in the mixed-mode e-learning environment? A study of software usage instruction," Computers \& Education, vol. 58, pp. 338-349, January, 2012.

[8]. R. Ellis, and P. Goodyear, Students' experiences of e-learning in higher education: the ecology of sustainable innovation, 1st ed., New York: Routledge, 2013, pp. 20-29.

[9]. J. Seale, E-learning and disability in higher education: accessibility research and practice, 1st ed., New York: Routledge, 2014, pp. 32-58. 